\title{
Acquisition of English Prepositions among Iraqi Secondary School Students in Kuala Lumpur-Malaysia
}

\author{
Hani Shakir (Corresponding author) \\ Faculty of Modern Languages and Communication, University Putra Malaysia, Malaysia \\ E-mail: hanishakir.ird@gmail.com \\ Bilal Huri Yaseen \\ Faculty of Modern Languages and Communication, University Putra Malaysia, Malaysia \\ E-mail: byaseen2010@gmail.com
}

Doi:10.7575/aiac.alls.v.6n.5p.157

Received: 26/05/2015

URL: http://dx.doi.org/10.7575/aiac.alls.v.6n.5p.157

Accepted: 01/08/2015

\begin{abstract}
The study focuses on the acquisition of English prepositions among students of Iraqi secondary school in Kuala Lumpur, Malaysia. Participants in the study were (20) students all of them at sixth level. The researchers studied the students' responses to the given test to investigate the problematic prepositions of English language that Iraqi English as foreign language (EFL) learners have in their everyday and academic usage; and investigate the way that EFL Iraqi learners differentiate between using English and Arabic prepositions. The major finding in this study is that the main reason for all the errors is the dominance of the mother tongue (MT) on English language (EL), especially with Arabic language having a syntactic structure when imposed on EL that too with Arabic meaning on EL. The dominance and influence of one's MT is a major challenge in using the EL in the right way by Iraqi EFL learners. In a subconscious manner, Iraqi EFL learners tend to use or impose their MT's syntactic, semantic structures and patterns on EL. Arabic and English have different number of prepositions and word-to-word equivalents of prepositions cannot be found between Iraqi Arabic and English Languages. Iraqi EFL learners are influenced by the prepositional system of their MT (Arabic) when they intend to use the prepositions in EL and this leads to errors and lack of idiomaticity. Inaccuracy is a result of this, which is reflected in class hours for EFL learners.
\end{abstract}

Keywords: Arabic Preposition, English Preposition, Iraqi EFL Learners, English as Foreign Language (EFL)

1. Introduction

Regardless of one's mother tongue, as far as English as Foreign Language (EFL) learners are concerned, prepositions in English language have always been difficult to deal with (Celce-Murcia, 1983:250). This happens mainly because the EFL learners tend to relate the prepositions in EL with the prepositions in their mother tongue. Difference in preposition numbers and a lack of one to one mapping between the languages is the root cause. Apart from this, as prepositional usage in EL is highly idiomatic, specifically with phrasal verbs and prepositional verbs, English prepositions' nuances in an idiomatic manner of using makes it difficult for EFL learners. This at times also makes native EL speakers unsure of the proper form of usage (Gethin, 1983: 161). Also (Alayesh 2012) noticed that prepositions are one of the most difficult aspects of English faced by students during learning. He also has been noticed that the extent of the difficulty is not always stable, but students may face much more difficulties in using some English prepositions than others. Another issue is that prepositions in EL generally are much polysemous and they represent a conceptual ontological category. This makes it difficult for the EFL learners in the decision making regarding which prepositions to use. This challenge is multiplied when they realize that the conceptual mapping in their MT is different from English language. As such, prepositional usage is the biggest challenge that makes fluency in terms of grammar and accuracy of EFL learners a challenge.

In the case of Iraqi EFL learners, cross-linguistic differences in the languages' prepositional system make prepositions a challenge. Both the languages have different number of prepositions and word-to-word equivalents of prepositions cannot be found between Iraqi Arabic and EL languages. Iraqi EFL learners are influenced by the prepositional system of their MT (Arabic) when they intend to use the prepositions in EL and this leads to errors and lack of idiomaticity. Inaccuracy is a result of this, which is reflected in class hours for EFL learners (Zughoul, 1973).

The fundamental English prepositions were "at, in and on" when used by Iraqi students in English class at Iraqi school in Kuala Lumpur, Malaysia. The study intends to address these challenges faced by them by comparing the EL and Arabic language prepositional system.

1.1 Problem Statement

The main issue here is that not every preposition in Arabic language has exact equivalent in English and vice versa. Next issue is that both English prepositions and Arabic language prepositions have stern and specific usage and meaning, which indicates only time, space or following a specific word. For space and time, the most challenging 
Arabic language prepositions are “in” and “on”. In addition, Iraqi EFL students normally use or avoid any English prepositions as per their Arabic usage.

\subsection{Objective and Research Questions}

This paper examines the issues faced by Iraqi EFL learners in Malaysia with the fundamental English prepositions "in" and "on" and intends to address these English prepositions based issues via a comparative study of the prepositional systems in both languages. The study also examines whether the preposition usage is grammatical or not.

1- Which are the problematic prepositions of English language that Iraqi EFL learners have?

2- How the EFL Iraqi learners differentiate between using English and Arabic prepositions?

3- How often and do the Iraqi EFL learners use prepositions in grammatical contexts or not?

\section{Methodology}

\subsection{Research Design}

This study is a qualitative study to show and explain the usage of prepositions by Iraqi EFL learners.

2.2 Instruments

A test (picture description test) will be done for examining the ability of the student for distinguishing between prepositions in both languages.

Each test version has (6) images. Each (2) images represent a type of preposition (Directional preposition, Locational Preposition and both). It will be given to the participants of the study and asked to describe the prepositions regarding of what is figured in the image in English and Arabic languages. The test will emphasize on "in and on" and the way in which Iraqi EFL students will use it.

\subsection{Participants}

The study sample group is (20) male and female students, chosen via random sampling from the Iraqi secondary school in Malaysian capital city. The sample consists of EFL learners of $6^{\text {th }}$ level and they are all aged (17) and above.

\subsection{Data Analysis}

This project has a design for analyzing the prepositional misuse among Iraqi EFL learners in Malaysia of L2 writing by using Hubbard, Johns, Thorton, Wheeler (1996, pp. 135-141) and Ellis (1997, pp. 15-20) for data collection:

- Choosing language corpus

- Error identification

- Classification of prepositions' functions

- Explanation of various types of "in" and "on" prepositions

\section{English and Arabic Prepositions Comparison}

\subsection{The Preposition (fii...in)}

Many EFL researchers have agreed to the fact that prepositional usage is one area, which makes EFL learners the right usage of the language difficult. This is much visible in the case of languages such as Arabic that has a strong structure. Even though both Arabic and English languages have similarities in many ways, the number and usage of prepositions makes them different and difficult for the EFL learners to comply with. For instance out of nearly (30) Arabic prepositions (Abbas Hasan, 1961), only (6) are prominent and this in the case of EL is more than (150) prepositions (Josef Essberger, 2000). Those prominent Arabic prepositions are "min, ila, ala, bi, li, and fi" (from, to, to, on, in, to and in, successively).

Two entities and their relationship are expressed by a preposition. It indicates a link in space (between two objects) and or a link in time (between two happenings) and or an in-depth abstract association (govt. bodies). Hence, the initial characteristics are that neither Arabic language prepositions nor EL prepositions can be alone and that they make sense via context based usages.

Number of prepositions in Arabic language is much less than in English, which is the next characteristics. At the very same time, each preposition serves various purposes in the language. Time or space may be expressed by the same preposition preceded by a noun, adverbs, verb or an adjective and it may be used idiomatic.

The main issue here is that not every preposition in Arabic language has exact equivalent in EL and vice versa. Next issue is that both English prepositions and Arabic language prepositions have a stern and specific usage and meaning, which indicates only time, space or following a specific word. For space and time the most challenging Arabic preposition is "fii" and "on".

The $1^{\text {st }}$ example, Arabic preposition "fii" is a preposition in Arabic language which is used as (in, into, at, on, and inside... etc.). As such, this preposition has a great semantic ability in colloquial as well as standard use of language. It is the filer via the equivalents of all these prepositions in English, which have to pass through. It is used for denoting time and place and takes place with various Arabian words in abstract as well as metaphorical usages. Hence "fii" and other Arabic prepositions, interferes in using and selecting English ones.

(Fii)

1. The boy sleeps in bed. (Correct response) (In)

2. The spring season will begin in $1^{\text {st }}$ of March. (On)

3. The souvenirs have been bought in the end of the tour. (At)

4. Joyful things I did in my previous weekend. (During)

5. Israa arrived faculty in happily. (?)

6. The eagle is flying into the sky. (In) 
The $1^{\text {st }}$ English preposition which probably will be produced as Arabic language preposition "fiii" equivalent is "in" as shown in the $1^{\text {st }}$ sentence where rightly used. Anyhow it is incorrectly chosen instead of "on, at, during, "?", and into" in the $2^{\text {nd }}, 3^{\text {rd }}, 4^{\text {th }}$ and $5^{\text {th }}$ sentences. On the other side, Iraqi students in this study may use this preposition as well as it related equivalents by interchanging them as indicated in the $6^{\text {th }}$ sentence.

Another issue, Iraqis use or avoids some of the English prepositions according to Arabic usage. Hence, via literal word to word translation is considered by the students especially when Arabic context needs a preposition (or needs none), learners do respond wrongly as shown in the following examples:

7. Nadia enjoyed the movie.

The literal translation of this sentence is

Either Nadia enjoyed with the movie.

$\underline{\mathrm{Or}} \quad$ Nadia enjoyed from the movie.

In Arabic, it is mandatory for inserting a preposition for making an association between enjoyment and the film, which causes enjoyment. With the absence of such a preposition, the Arabic here has no meaning.

As such, Iraqi EFL learners are prone to insert non-essential prepositions when they use EL for expressing themselves. On the other side, they may avoid the essential prepositions as shown in the below examples:

8. We bought corn flakes, when we reached in Paris.

9. I have to spend at the vacation in New York for two weeks.

These are the proper responses in English. The prepositions "in, for, and of" has to be included for forming a link between reaching and place to which was reached; at, and the spending the vacation in New York and the time to be spent there. Without these prepositions, the sentences above has nil meaning in EL. Anyhow, these sentences' literal translations doesn't need such prepositions as the link exists in Arabic language without them as exhibited in the Figure (1).

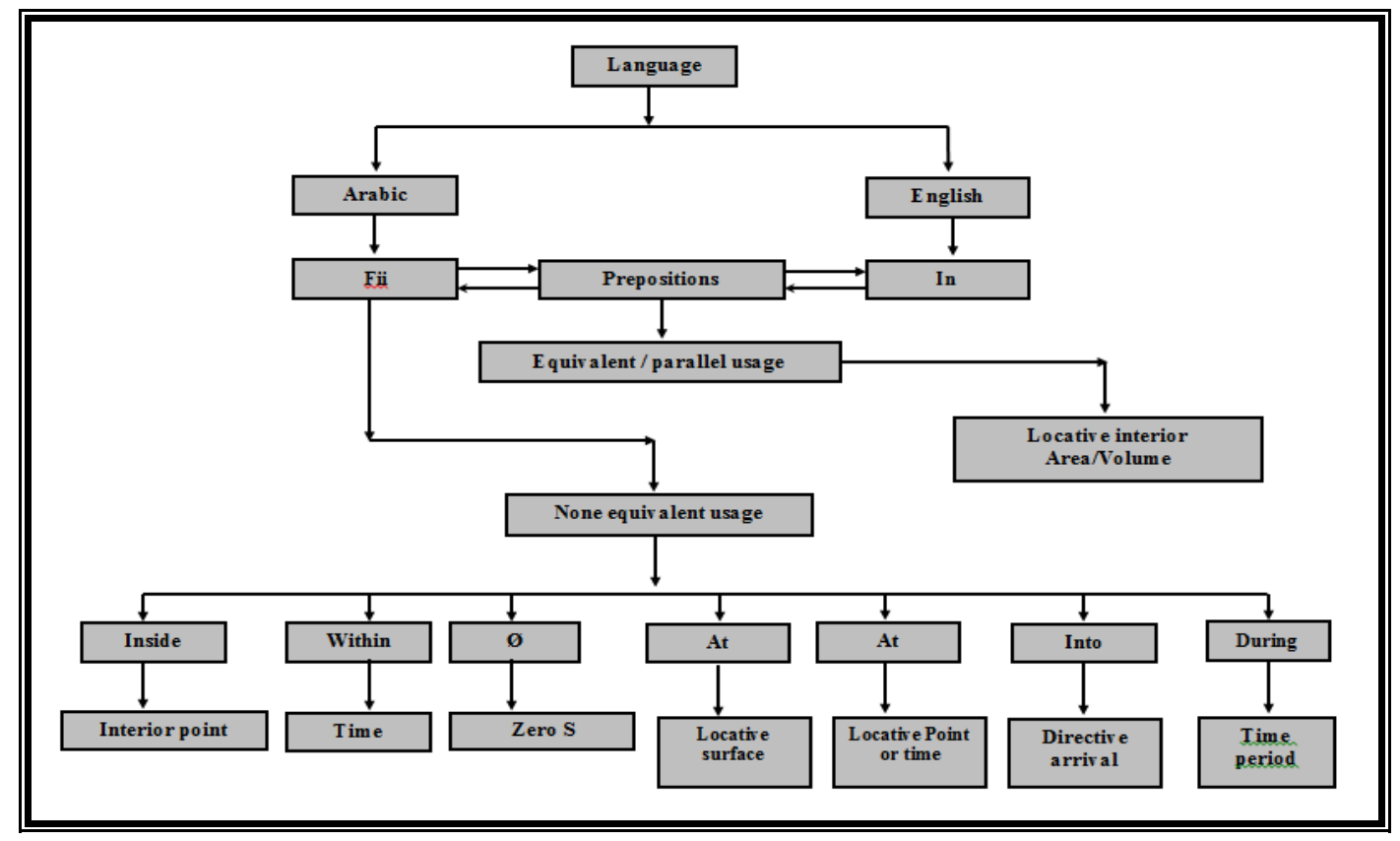

Figure 1. Flowchart of Arabic preposition "Fii" in comparison with English preposition "In"

\subsection{The Preposition (ala...on)}

The $2^{\text {nd }}$ example "Ala' is the Arabic prepositional equivalent of English preposition “on, over, above, at and onto". They all have same equivalency and usage in real life usage, as per the statements of Iraqi students involved in the study. There is no differentiation that could be made is using these prepositions, "on", is used only as shown in the examples below: -

1. Mazin has seen soccer on TV. (On)

2. The helicopter is flying on me. (Above)

3. Saad has jumped on the wall. (Over)

4. They have sat on the table. (At)

5. Rashid is coming on Ten o'clock. (At)

6. The crab was washed-up on the beach. (Onto)

As seen in the $1^{\text {st }}$ sentence above here, "ala" is the $1^{\text {st }}$ Arabic preposition used which the equivalent of English preposition "on". Anyhow this is wrongly chosen of "over, above, at and onto" in $2^{\text {nd }}, 3^{\text {rd }}, 4^{\text {th }}, 5^{\text {th }}$ and $6^{\text {th }}$ sentences above. 
The main reason for this issue is that Iraqi EFL learners depend on their MT for literal translation before forming EL pattern. That is, they translate English to Arabic and then back to EL, word-to-word. Hence, Arabic Language interference is the root cause of the issue. Correct preposition is also difficult to make as the EL patterns and Arabic language patterns are different as in Figure (2).

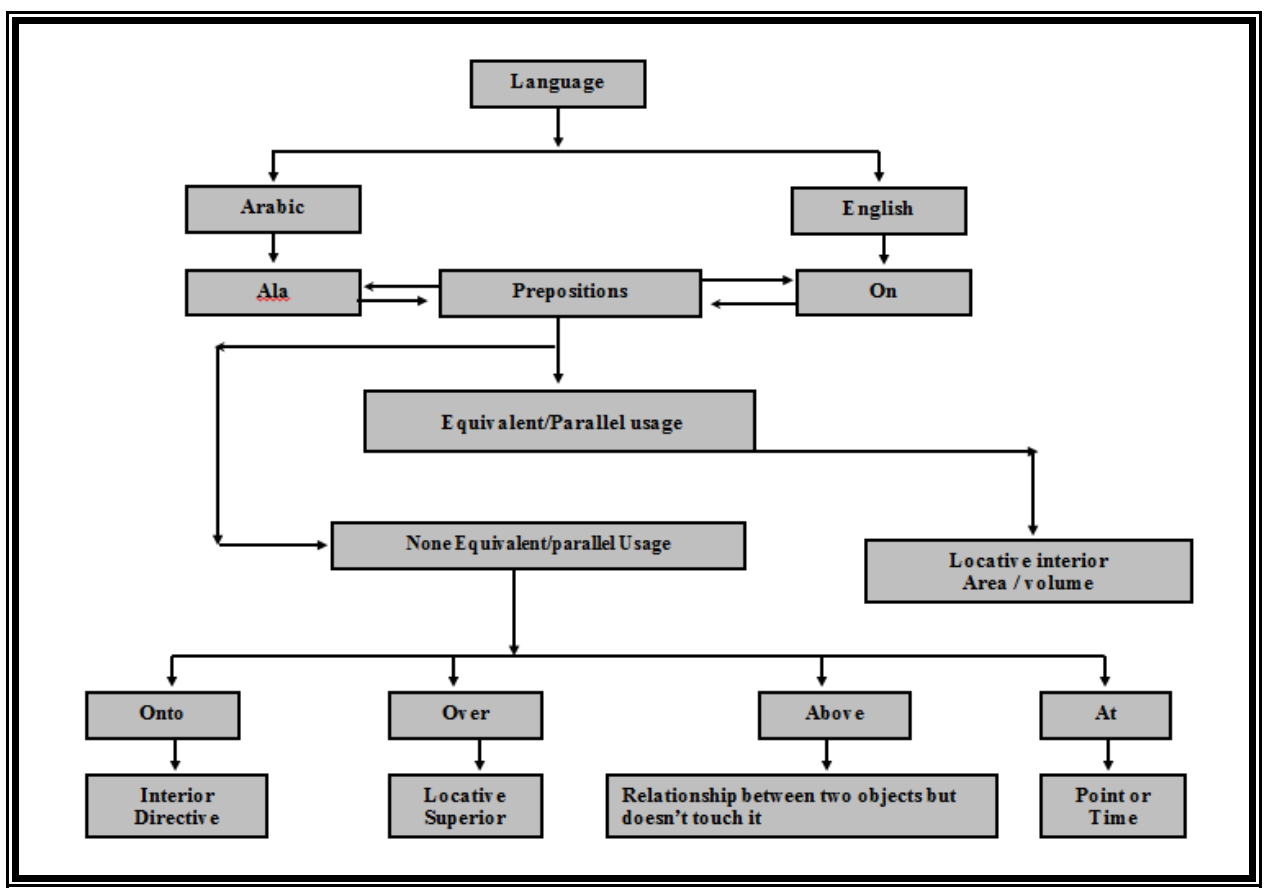

Figure 2. Flowchart of Arabic prepositions "ala" in comparison with English Preposition "on"

\subsection{English and Arabic System Comparison}

There are three prepositions in English "on, in and at" which are used for indicating positioned point in time and another preposition "during" for indicating positioned time. In Arabic language, anyhow, "fii" is meant for indicating the meaning and the uses of all the above EL prepositions. As such is equivalent to:

1. (On) It is an equivalent of "ala and fii" in Arabic language, it shows a positioned point in time and it is used along with phrases that refer to days and dates as they are regarded as a "surface" or "line". For instance:

- I arrived on time. (An exact point in time)

- I work on Sundays.

2. (In) It is an equivalent of "fii" in Arabic language, it shows a positioned point in time and is used along with phrases which represents parts of days (with "at night", "at midday" as exceptions ... etc.), month, years etc. as they are regarded as an "area", e.g. in the morning". It is also used for denoting unspecified point during a period of time. For example, "In the evening" = "during the evening".

3. (At) It is an equivalent of "fii" in Arabic language. It shows a positioned point in time and is used with hours, as they are regarded as a "point" e.g. "At 3 o'clock", also an exceptionally in "at night" as night is considered as a point.

4. (During) It is an equivalent of "fii" in Arabic language; it shows the passage of a time period. For example, "during the journey" the time during which the travelling happened is regarded as an imaginary line, which is similar to the route of journey.

Arabic language has no differentiation between the above ranges of usages, because fii indicates a point of time and time period. Unlike "fii", "ila and min" which represent movement toward or away from a particular point in time, it shows the similar or same concepts as their English equivalents "to" and "from". Toward or away from a particular point in time, shows the similar or same concepts as their English equivalents "to" and "from". 
5. (For) It indicates time duration and is used in the expressing movement too. Its Arabic equivalent is "li", which holds the same meaning as well as usage.

6. (Into and to) shows movement and "in" shows no movement in EL, with "fii" equivalent to both in Arabic language.

7. Unlike "fii", "ila" shows movement of an object towards a point. As such, its usage and meaning is equivalent to its EL counterpart "to". For Example: Ali went to the school.

8. Like "fiii", "min" has different equivalents in EL. It shows separation from a particular area or point or volume or from a line or surface. As such, it translates EL prepositions "from", "away from", "out of" and "off."

9. “Ala" It is the Arabic preposition, which the EL equivalent is "on, over, above and onto". "On" shows locative Surface, is generally used in order to show the relationship between two things which can be touched. Unlike on, "over" and" "above" is used for expressing an association between two things which cannot be touched. "Onto", "on" shows surface locative and "to", shows movement directive.

10. "Bï" and "fiii" are Arabic prepositions of which the EL equivalent is "in and at".

11. "Li" is the Arabic preposition of which the EL equivalent is "to and for".

\section{Findings}

Researchers reveal three main results:

1- $\mathbf{( 4 0 \% )}$ ) percent $(\mathbf{8})$ students used prepositions in correct meaning, while $(\mathbf{6 0 \%})$ percent students (12) in the wrong meaning.

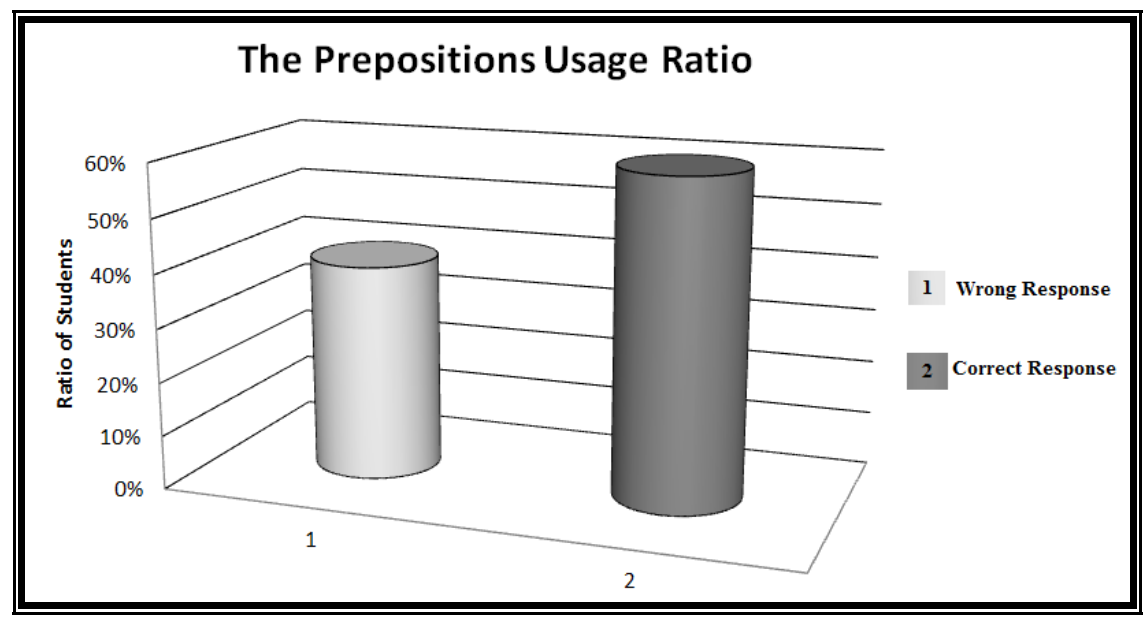

Figure 3. The chart shows the ratio of participants responses (Correct - Wrong)

2- Students from Iraq whose MT is Arabic seem to subconsciously impose their language patterns and structures in EL. Their MT's prepositions have a major influence on EL. This is found to be the main reason for their errors.

3- The main reason for all the errors is the dominance of MT on EL, especially with Arab language having a syntactic structure when imposed on EL that too with Arabic meaning on EL.

It has been realized from the results of this study that EL prepositions makes EFL learning difficult for foreign students. In this study, Iraqi students were found to commit errors in their tests because of the usage of prepositions in EL.

Arabic language and EL prepositions even though have certain similarities; they differ in terms of numbers and usage. In the case of number, EL has over 30 prepositions, whereas Arabic language only has six of them.

One main issue is that there is no one to one replica for an Arabic preposition in English or vice versa. Secondly, no definite usage or meaning exists for any prepositions in both the languages. This depends on the time or space. For instance, the "fii" is a preposition in Arabic language that is used as (in, into, at, on, and inside). As such, this preposition has much semantic power in standard as well as colloquial use of language; it is the filer via which the equivalents of all these prepositions in English have to pass through. It is used for denoting time and place and takes 
place with various Arabic words in abstract as well as metaphorical usages. Hence "fii" and other Arabic prepositions, influences the usage and selection of English prepositions.

English language allows certain flexibility when it comes to its prepositions and prepositional usages, unlike many other languages. This flexibility in usage at times confuses EFL learners, especially Iraqi students whose MT does not allow such flexibility of usage. These are the two main pitfalls in EFL learners' usage of EL prepositions.

\section{Conclusion}

It can be concluded that the dominance and influence of ones MT is a major challenge in using the EL in the right way by Iraqi EFL learners. In a subconscious manner, Iraqi EFL learners tend to use or impose their MT's syntactic, semantic structures and patterns on EL. The extent of influence of this depends on various elements such as the degree of relatedness of the foreign language and mother tongue, proficiency of command over foreign language and similarities and dissimilarities in the cultural contexts in which background the languages are being used.

\section{References}

Abbas, H.H. (1985). Some Remarks on the Prepositions (in), (on) and (to) in English and Standard Arabic. $A L$ Mustansiriya Literary Review, 11, P.41-50.

Alayesh, M. A. (2012) The Effect of Arabic Prepositions On the use of English Prepositions, Faculty of Specific Education - Mansoura University.

Celce - Murcia, M., and Larsen Freeman, D. (1983). The Grammar Book. Rowley, MA: Newbury House Publishers.

Coleman, S. (1996). Teaching Some Common Prepositions. -, 34(1), 42-50.

Dagut, M., and Laufer, B. (1985). Avoidance of Phrasal Verbs-A Case for Contrastive Analysis. Studies in Second Language Acquisition, 7(1),73-90.

Ellis, R. (1997) SLA Research and Language Teaching. Oxford :Oxford University Press.

Gass, S., and L. Selinker (1983). Language Transfer in Language Learning. MA: Newbury House Publishers, Inc.

Hubbard , P., Jones, H., Thorton, B., Wheeler, R. (1996) A Training Course for TEFL - Oxford : Oxford University Press .

Lakkis, K., and Abdol Malak. M. (2000). Understanding the Transfer of Prepositions: Arabic to English, Essex: Longman, 38(3), July - September 2000, p.26.

Koda, K. (1988). Cognitive Process in Second Language Reading: Transfer of L1, Reading Skills and Strategies. Second Language Research, 4,133-156.

Pittman, G. A. (1966). Activating the Use of Prepositions. London: Longman, Green and Co., Ltd.

Ringbom, H. (1992). On L1, Transfer in L2 Comprehension and L2 Production. Language Learning, 42, 85-112.

Zughoul, M. R. (1973). Teaching English Prepositions to Arab Students. Unpublished MA Thesis, American University of Beirut. 